\title{
Qualidade da polpa da carpa Húngara transportada viva ou no gelo
}

\author{
Hungarian carp minced quality transported live or on ice
}

\section{Márcio Martinez Echevenguái ${ }^{*}$ Walesca Oliveira Echevenguá ${ }^{I I}$ Ana Amélia Carbonera ${ }^{\text {II }}$ Carlos Prentice-Hernández ${ }^{\text {II }}$ Mario Roberto Chim Figueiredo ${ }^{\mathrm{I}}$}

\section{RESUMO}

No presente trabalho foi estudado o efeito do método de transporte (peixe vivo ou no gelo) na qualidade da polpa da carpa húngara Cyprinus carpio proveniente de cultivos em que eram alimentadas com ração, dejetos de suínos ou dejetos de frangos. A polpa foi moída, embalada a vácuo em embalagem de polietileno e conservada sob refrigeração $2 \pm 1^{\circ} \mathrm{C}$. Foram realizadas análises de rendimento de carcaça $e$ composição proximal do músculo. As análises de BVT (bases voláteis totais), $\mathrm{pH}, \mathrm{IP}$ (índice de peróxidos) e TBA (ácido tiobarbitúrico) da polpa foram realizadas no $1^{\circ}, 4^{\circ}$, $7^{\circ}$, $15^{\circ} e$ $30^{\circ}$ dias de conservação. O rendimento da polpa das carpas cultivadas com dejetos de suínos e transportadas no gelo foi estatisticamente superior às transportadas vivas, atingindo 41,5\%. As alimentadas com ração e com dejetos de frango não revelaram efeitos dos métodos de transporte $(P>0,05)$. As principais frações nutritivas (proteínas e lipídios) não mostraram efeitos $(P>0,05)$ do método de transporte avaliado. As $B V T, p H, I P$ e TBA evidenciaram interações $(P<0,05)$ entre os sistemas de cultivo e os métodos de transporte. BVT e pH estiveram dentro dos valores estipulados pela legislação brasileira. IP e TBA foram baixos (máximo de 14,73mg peróxido $\mathrm{kg}^{-1}$ e 0,480mg malonaldeído $\mathrm{kg}^{-1}$, respectivamente), evidenciando que as polpas teriam tempo de conservação superior a 30 dias. A qualidade da polpa não foi influenciada pelo método de transporte.

Palavras-chave: carpa, polpa, sistema de transporte, qualidade.

\section{ABSTRACT}

The objective of this research was to evaluate the effect of rearing method (fed on dry diet, pig manure, or chicken manure) and the method of transport (live fish or on ice) on the quality of minced meat of Hungarian carp Cyprinus carpio. In order to obtain the minced meat, the muscle was triturated, vacuum wrapped in polyethylene packing and conserved under refrigeration $2 \pm 1^{\circ} \mathrm{C}$. Analyses of carcass yield and muscle proximal composition were carried out. The effect of storage time $(1,4,7,15$, and 30 days) was analyzed in terms of TVB (total volatile bases), pH, PI (peroxides value) and TBA (thiobarbituric acid). Carcass yield of the carps cultivated on pig manure and transported on ice was statistically higher than those transported alive, reaching $41.5 \%$. However, there was no significant difference of carcass yield of carps fed on dry diet or chicken manure independent of the transport method $(P>0.05)$. Protein and lipid content were not significantly different $(P>0.05)$ when considering the transport methods. TVB, $p H, P I$ and TBA showed interactions $(P<0.05)$ between rearing methods and the transport methods. TVB and $\mathrm{pH}$ were in accordance to the values stipulated by the Brazilian legislation. PI and TBA were low (maximum of $14.73 \mathrm{mg}$ peroxide $\mathrm{kg}^{-1}$ and $0.480 \mathrm{mg}$ malonaldeyd $\mathrm{kg}^{-1}$, respectively), showing that the minced meat can be preserved longer than 30 days. Quality of the minced meat was not affected by the transport method.

Key words: carp, minced, transport system, quality.

\section{INTRODUÇÃo}

Por ser alimento de fácil deterioração, o pescado exige muitos cuidados de manuseio (SAKERSAMPAIO \& VIEIRA, 2003). Os processos de alteração geralmente seguem o mesmo curso e ocorrerão independentemente da origem, da procedência (HUSS, 1988) e da forma como o pescado é manuseado, mas a velocidade com que eles se instalam pode ser reduzida, de modo que a etapa posterior de processamento seja

IDepartamento de Oceanografia, Laboratório de Aquacultura Continental, Fundação Universidade Federal do Rio Grande (FURG),

Rio Grande, RS, Brasil. CP 474, 96201-900. E-mail: mechevengua@yahoo.com.br ou dodchim@furg.br.*Autor para correspondência.

IDDepartamento de Química, Laboratório de Tecnologia de Alimentos, FURG, Rio Grande, RS, Brasil 
possível (BONNELL, 1994). A manipulação do pescado fresco entre a captura e o processamento é crucial para a qualidade do produto final (RIBEIRO et al., 2005). Os métodos de captura têm influência acentuada em relação ao intervalo de tempo necessário para que o rigor mortis se instale. Assim, o pescado submetido a estresse durante a captura terá o período de rigor mortis reduzido devido ao gasto excessivo de glicogênio (STANSBY, 1968), não produzindo ácido lático suficiente, favorecendo a proliferação microbiana, já que o pH aumenta (SÁ, 2004). É importante retardar o aparecimento do rigor mortis, pois a maioria dos fenômenos relacionados à deterioração somente se acentua após seu término (NEIVA, 2004). Os peixes podem debater-se muito antes de sua morte, prejudicando a qualidade e o tempo de estocagem em gelo (STANSBY, 1968). A garantia de que o pescado produzido em cativeiro origina produtos de qualidade é dada pela capacidade de entrega de peixes vivos aos beneficiadores (SOUZA, 2001). O pescado é transportado vivo em tanques aerados até a indústria processadora e, quando submetido a jejum, se recupera do estresse mais rapidamente (BRESSAN, 2001).

Baixas temperaturas são usadas para retardar reações químicas e a ação das enzimas do alimento, além de minimizar ou parar a atividade dos microrganismos (FRAZIER \& WESTHOFF, 1998). O gelo pode ser usado como o principal método de conservação ou numa preservação temporária até que outro processo seja aplicado. Alimentos perecíveis podem ser estocados em gelo por tempo limitado. $\mathrm{O}$ processamento mínimo baseia-se fundamentalmente na teoria de obstáculos, proposta por LEISTNER \& RODEL (1976). A ação da atmosfera modificada a vácuo associada a temperaturas de refrigeração permite ampliar a vida de prateleira do pescado, minimizando gastos com congelamento e permitindo a obtenção de produto de alta qualidade por mais tempo (SEAFOOD, 2006). O acondicionamento em embalagem com atmosfera modificada, a vácuo, consiste na exposição dos alimentos à ausência de ar, controlando o desenvolvimento de microrganismos, a ação enzimática e a oxidação, principais mecanismos de deterioração (SAINZ, 2001).

A relativa escassez de informações sobre como melhor conservar os peixes após a despesca evidencia a necessidade de estudos para serem estabelecidos os melhores métodos de abate, as melhores condições de armazenamento após morte e outros fatores que facilitam os processos e melhoram a qualidade dos peixes de água doce (VIEGAS, 2004).

Neste trabalho se estudou o efeito do sistema de transporte (vivas ou no gelo) na qualidade da polpa da carpa húngara Cyprinus carpio vinda de diferentes sistemas de cultivo.

\section{MATERIAL E MÉTODOS}

Foram utilizados peixes provenientes de sete localidades no Rio Grande do Sul, escolhidas porque criavam em policultivo (35\% de carpa húngara Cyprinus carpio, $27 \%$ de carpa-capim Ctenopharyngodon idella, 19\% de carpa prateada Hypophthalmichthys molitrix e 19\% de carpa cabeçagrande Aristichthys nobilis). Os viveiros possuíam $1000 \mathrm{~m}^{2}$ e o tempo de cultivo de um ano. Em três localidades (Rio Grande, Capão do Leão e Morro Redondo), os peixes eram alimentados com ração comercial Supra ${ }^{\circledR}, 28 \%$ de proteína bruta. A densidade de estocagem foi de um peixe $\mathrm{m}^{-2}$, freqüência alimentar de uma vez ao dia, de 1-1,5\% do peso vivo. Duas outras localidades (Roca Sales e Colinas) possuíam cultivos consorciados com suínos e duas (Roca Sales e Estrela), consorciados com frangos. Nestas, a densidade era de um peixe $4 \mathrm{~m}^{-2}$, freqüência alimentar de duas a três vezes ao dia, totalizando $50 \mathrm{~kg}$ de dejetos por semana.

Após a despesca, três peixes eram armazenados em caixa de isopor com gelo potável (1,0kg peixe: $1,5 \mathrm{~kg}$ gelo) e três colocados em tanque de $250 \mathrm{~L}$ com água, com aeração, fixando-se o tempo de permanência dos peixes em 14 horas. Decorrido este tempo os peixes do gelo eram lavados com água corrente e eviscerados e novamente lavados em água corrente e após com água clorada (5ppm) (OETTERER, 2002). Sua pele e cabeça eram retiradas e, após o espalmamento, os peixes eram cortados em pequenos pedaços para a moagem, obtendo-se a polpa. Esta era embalada a vácuo em embalagens de náilon polipropileno de cinco camadas, de alta barreira de oxigênio, e climatizada a $2 \pm 1^{\circ} \mathrm{C}$. Nos peixes vivos, a água foi reduzida e adicionou-se gelo, para facilitar o abate, corforme descrito anteriormente.

Os peixes foram pesados inteiros, assim como a cabeça, as vísceras e a polpa utilizadas para as demais análises. Os resíduos (nadadeiras, pele, espinhas e sangue) foram estimados por diferença. A polpa foi dividida em porções, colocadas em embalagens identificadas (local do viveiro, número e

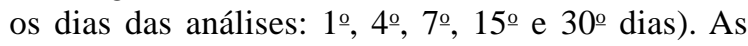
amostras foram embaladas a vácuo por termo-soldagem e, posteriormente, colocadas em climatizadora (refrigeração a $2 \pm 1^{\circ} \mathrm{C}$ ). Aproximadamente $60 \mathrm{~g}$ de músculo do pescado, da região acima da linha lateral, próxima à caudal, foi separada, embalada e refrigerada nas mesmas condições.

A composição proximal (proteína, lipídio, umidade e cinzas) foi obtida segundo metodologia da 
A.O.A.C. (2000), na polpa e no músculo. Apenas na polpa foram analisados: índice de peróxidos (IP), utilizando os lipídios extraídos pelo método de BLIGH \& DYER (1959), e titulados por oxi-redução (A.O.A.C., 2000); índice de ácido tiobarbitúrico (TBA), segundo YU \& SINNHUBER (1957), adaptado por MAIA (1980); bases voláteis totais (BVT), determinadas segundo BRASIL (2007b); e pH, pelo método citado por LANIER \& LEE (1992). Foi calculado o valor calórico da polpa a partir dos teores de proteína, lipídios e carboidratos (FRANCO, 1992; BRASIL, 2003).

Foram realizadas análises de variância, aplicando-se o teste de Tukey para comparação das médias, sempre que se observou diferença significativa $(\mathrm{P}<0,05)$. As interações de efeitos dos sistemas de criação com os métodos de transporte foram analisadas.

\section{RESULTADOS E DISCUSSÃO}

Os valores médios de rendimento de carcaça estão apresentados na tabela 1 . Polpa, cabeça e vísceras não apresentaram interações significativas entre o sistema de cultivo e o método de transporte, porém, foi verificada interação significativa para os resíduos. O teor de vísceras no tratamento de dejetos de suínos foi significativamente menor que no tratamento ração, sendo as carpas, neste último, transportadas no gelo. Os resíduos das carpas do tratamento de dejetos de suínos e transportadas vivas foram significativamente superiores aos das tratadas com ração e transportadas no gelo e das tratadas com dejetos de frangos, transportadas vivas ou no gelo. As carpas cultivadas com dejetos de suínos e transportadas no gelo tiveram percentual de polpa significativamente maior que as transportadas vivas. Os teores de resíduos foram maiores em carpas transportadas vivas.
A tabela 2 mostra que na polpa os resultados da umidade, proteína, lipídios, cinzas e valor calórico não evidenciaram interações significativas entre o sistema de cultivo e o método de transporte. Entretanto, a polpa do tratamento dejetos de frangos teve percentual de umidade mais elevado quando transportadas no gelo. No músculo, não houve interações significativas entre o sistema de cultivo e o método de transporte para os valores de umidade, proteína, lipídios, cinzas e valor calórico. O nível protéico no músculo do tratamento ração, mais elevado do que o nível protéico no músculo do tratamento dejetos de frangos, pode ser um indício de deficiência protéica ou desbalanceamento de aminoácidos na alimentação das carpas tratadas com dejetos de frangos, refletidos no músculo. Não ocorreu diferença significativa para a umidade, a proteína, os lipídios e o valor calórico da polpa obtida nos três tratamentos e nos dois métodos de transporte. Contudo, a porcentagem de cinzas no tratamento dejetos de frangos foi superior quando os peixes foram transportados vivos.

No músculo não foram verificadas diferenças significativas entre os teores de umidade, proteína, lipídios e cinzas nos tratamentos e nos métodos de transporte. Para o valor calórico, foi observada diferença no tratamento ração, apresentando quantidade maior de calorias quando os peixes foram transportados vivos. Maiores níveis de proteína, cinzas e valor calórico foram observados nos peixes transportados vivos. Este valor se refletiu em menor teor de umidade da polpa nas transportadas vivas, apenas para o tratamento dejetos de frangos. A variabilidade inexplicável dos resultados da composição proximal pode ter ocorrido em função de diferenças morfológicas nos peixes capturados.

Na tabela 3 são apresentados os resultados para BVT, pH, IP e TBA da polpa de carpa húngara em

Tabela 1 - Rendimento de carcaça em função do sistema de cultivo e do método de transporte de carpas.

\begin{tabular}{|c|c|c|c|c|c|c|}
\hline Tratamento & & Transporte & Polpa (\%) & Cabeça (\%) & Vísceras (\%) & Resíduos (\%) \\
\hline \multirow{2}{*}{ ração } & & vivo & $37,90^{\mathrm{aA}}$ & $19,81^{\mathrm{aA}}$ & $13,46^{\mathrm{aAB}}$ & $28,83^{\mathrm{bAB}}$ \\
\hline & & no gelo & $38,14^{\mathrm{aA}}$ & $19,81^{\mathrm{aA}}$ & $18,10^{\mathrm{aB}}$ & $23,96^{\mathrm{aA}}$ \\
\hline \multicolumn{3}{|c|}{ DP } & 4,18 & 3,22 & 7,10 & 4,93 \\
\hline \multirow{3}{*}{ suínos } & & vivo & $36,05^{\mathrm{aA}}$ & $21,36^{\mathrm{aA}}$ & $9,65^{\mathrm{aA}}$ & $32,95^{\mathrm{bB}}$ \\
\hline & & no gelo & $41,49^{\mathrm{bA}}$ & $22,52^{\mathrm{aA}}$ & $7,81^{\mathrm{aA}}$ & $28,18^{\mathrm{aAB}}$ \\
\hline & DP & & 3,76 & 2,21 & 2,11 & 3,17 \\
\hline \multirow{3}{*}{ frangos } & & vivo & $40,80^{\mathrm{aA}}$ & $24,03^{\mathrm{aA}}$ & $11,90^{\mathrm{aAB}}$ & $23,27^{\mathrm{aAB}}$ \\
\hline & & no gelo & $36,80^{\mathrm{aA}}$ & $22,55^{\mathrm{aA}}$ & $13,64^{\mathrm{aAB}}$ & $27,00^{\mathrm{aAB}}$ \\
\hline & DP & & 8,31 & 2,07 & 4,64 & 6,12 \\
\hline
\end{tabular}

Obs.: Médias seguidas de letras maiúsculas iguais na mesma coluna não apresentam diferença significativa (P>0,05) entre os tipos de tratamento. Médias seguidas de letras minúsculas iguais na mesma coluna não apresentam diferença significativa $(\mathrm{P}>0,05)$ entre os métodos de transporte, para cada tratamento. DP = Desvio padrão. 
Tabela 2 - Composição proximal e valor calórico da polpa e do músculo de carpa húngara em diferentes sistemas cultivo, transportadas vivas ou no gelo.

\begin{tabular}{|c|c|c|c|c|c|c|c|}
\hline Tratamento & & Transporte & Umidade (\%) & Proteína (\%) & Lipídios(\%) & Cinzas (\%) & VC (kcal $\left.100 g^{-1}\right)$ \\
\hline \multirow{3}{*}{\multicolumn{2}{|c|}{ ração }} & & & Polpa & & & \\
\hline & & vivo & $78,57^{\mathrm{a}}$ & $18,26^{\mathrm{a}}$ & $1,54^{\mathrm{a}}$ & $1,33^{\mathrm{a}}$ & $86,86^{\mathrm{a}}$ \\
\hline & & no gelo & $78,25^{\mathrm{a}}$ & $18,67^{\mathrm{a}}$ & $1,38^{\mathrm{a}}$ & $1,40^{\mathrm{a}}$ & $87,05^{\mathrm{a}}$ \\
\hline & $\mathrm{DP}$ & & 1,67 & 2,19 & 1,00 & 0,52 & 9,32 \\
\hline \multirow{2}{*}{ suínos } & & vivo & $78,18^{\mathrm{a}}$ & $19,32^{\mathrm{a}}$ & $1,65^{\mathrm{a}}$ & $0,83^{\mathrm{a}}$ & $92,12^{\mathrm{a}}$ \\
\hline & & no gelo & $77,94^{\mathrm{a}}$ & $18,51^{\mathrm{a}}$ & $2,91^{\mathrm{a}}$ & $1,27^{\mathrm{a}}$ & $100,25^{\mathrm{a}}$ \\
\hline \multirow{4}{*}{ Frangos } & DP & & 1,52 & 1,26 & 1,71 & 0,45 & 15,47 \\
\hline & & vivo & $80,45^{\mathrm{ab}}$ & $17,15^{\mathrm{a}}$ & $1,50^{\mathrm{a}}$ & $1,11^{\mathrm{b}}$ & $82,05^{\mathrm{a}}$ \\
\hline & & no gelo & $81,43^{b}$ & $16,99^{\mathrm{a}}$ & $1,98^{\mathrm{a}}$ & $0,95^{\mathrm{a}}$ & $85,80^{\mathrm{a}}$ \\
\hline & $\mathrm{DP}$ & & 1,30 & 4,49 & 1,08 & 0,11 & 23,15 \\
\hline \multirow{4}{*}{ ração } & & & & Músculo & & & \\
\hline & & vivo & $78,61^{\mathrm{a}}$ & $21,19^{b}$ & $1,82^{\mathrm{a}}$ & $1,12^{\mathrm{a}}$ & $89,02^{\mathrm{ab}}$ \\
\hline & & no gelo & $78,62^{\mathrm{a}}$ & $19,74^{\mathrm{ab}}$ & $2,62^{\mathrm{a}}$ & $0,87^{\mathrm{a}}$ & $82,78^{\mathrm{a}}$ \\
\hline & DP & & 2,11 & 1,58 & 2,97 & 0,30 & 5,54 \\
\hline \multirow{2}{*}{ suínos } & & vivo & $77,55^{\mathrm{a}}$ & $20,56^{\mathrm{ab}}$ & $1,95^{\mathrm{a}}$ & $1,04^{\mathrm{a}}$ & $99,75^{\mathrm{b}}$ \\
\hline & & no gelo & $77,74^{\mathrm{a}}$ & $19,28^{\mathrm{ab}}$ & $1,68^{\mathrm{a}}$ & $1,05^{\mathrm{a}}$ & $92,23^{\mathrm{ab}}$ \\
\hline \multirow{4}{*}{ frangos } & DP & & 2,15 & 1,65 & 0,79 & 0,19 & 9,73 \\
\hline & & vivo & $79,19^{\mathrm{a}}$ & $17,73^{\mathrm{a}}$ & $0,82^{\mathrm{a}}$ & $1,06^{\mathrm{a}}$ & $78,27^{\mathrm{a}}$ \\
\hline & & no gelo & $79,62^{\mathrm{a}}$ & $17,82^{\mathrm{a}}$ & $0,85^{\mathrm{a}}$ & $1,03^{\mathrm{a}}$ & $78,88^{\mathrm{a}}$ \\
\hline & DP & & 1,06 & 2,13 & 0,44 & 0,08 & 10,67 \\
\hline
\end{tabular}

Obs.: Médias seguidas de letras iguais na mesma coluna não apresentam diferença significativa $(\mathrm{P}>0,05)$. DP = Desvio-padrão.

função dos sistemas de cultivo e métodos de transporte. Não foram verificadas interações significativas para BVT e IP. No entanto, para pH e TBA, houve interação significativa entre os sistemas de cultivo e os métodos de transporte. O valor de BVT obtido no tratamento ração e transportado no gelo foi superior ao tratamento dejetos de frangos e transportado no gelo. $\mathrm{O}$ pH do tratamento ração e transporte vivo foi menor que dos tratamentos ração e transporte no gelo, dejetos de suínos e transporte vivo e dejetos de frangos e transporte vivo. Para o IP as diferenças ocorreram entre os tratamentos ração e o transporte vivo e dejetos de frangos e o transporte vivo. Para o TBA ocorreram diferenças estatísticas entre os tratamentos ração e transporte vivo e dejetos de suínos e transporte no gelo.

Os valores obtidos para BVT, pH, IP e TBA nos primeiros 30 dias após o abate estão apresentados na tabela 4. Não foi observada diferença significativa entre os valores de BVT em nenhum dos tempos, em função dos sistemas de transporte, para as polpas provenientes dos tratamentos ração e dejetos de suínos. $\mathrm{O} \mathrm{pH}$ foi significativamente mais elevado no 7을 $15^{\circ}$ e $30^{\circ}$ dias nas polpas do tratamento ração, transportadas no gelo; já no tratamento dejetos de suínos, no $1^{\circ}$ dia, e no tratamento dejetos de frangos, no 7을 dia, o pH foi significativamente mais elevado nas polpas de carpas transportadas vivas.

Tabela 3 - Valores de BVT, pH, IP e TBA em função dos sistemas de cultivo e do método de transporte.

\begin{tabular}{|c|c|c|c|c|c|}
\hline & & $\mathrm{BVT}\left(\mathrm{mgN} 100 \mathrm{~g}^{-1}\right)$ & $\mathrm{pH}$ & IP (mg peroxide kg-1) & TBA (mgMA kg ${ }^{-1}$ ) \\
\hline tratamento & transporte & & & & \\
\hline \multirow{2}{*}{ ração } & vivo & $13,62^{\mathrm{bc}}$ & $6,4^{\mathrm{a}}$ & $11,22^{\mathrm{b}}$ & $0,286^{\mathrm{b}}$ \\
\hline & no gelo & $13,99^{c}$ & $6,6^{\mathrm{b}}$ & $9,97^{\mathrm{ab}}$ & $0,310^{\mathrm{bc}}$ \\
\hline \multirow{2}{*}{ suínos } & vivo & $13,37^{\mathrm{abc}}$ & $6,6^{\mathrm{b}}$ & $10,11^{\mathrm{ab}}$ & $0,220^{\mathrm{abc}}$ \\
\hline & no gelo & $13,09^{\mathrm{abc}}$ & $6,5^{\mathrm{ab}}$ & $10,34^{\mathrm{ab}}$ & $0,355^{\mathrm{bc}}$ \\
\hline \multirow[b]{2}{*}{ frangos } & vivo & $12,85^{\mathrm{ab}}$ & $6,7^{\mathrm{b}}$ & $7,89^{\mathrm{a}}$ & $0,199^{\mathrm{ab}}$ \\
\hline & no gelo & $12,39^{\mathrm{a}}$ & $6,5^{\mathrm{ab}}$ & $9,68^{\mathrm{ab}}$ & $0,146^{\mathrm{a}}$ \\
\hline
\end{tabular}

Obs.: Médias seguidas de letras iguais na mesma coluna não apresentam diferença significativa ( $\mathrm{P}>0,05)$. DP = Desvio-padrão.

Ciência Rural, v.38, n.7, out, 2008. 
Tabela 4 - Valores BVT, pH, IP e TBA em diferentes tempos e sistemas de transporte.

\begin{tabular}{|c|c|c|c|c|c|c|}
\hline \multicolumn{2}{|c|}{ Tempo (dias) } & $1^{\circ}$ & $4^{0}$ & $7^{0}$ & $15^{-}$ & $30^{\circ}$ \\
\hline Tratamento & Transporte & \multicolumn{5}{|c|}{$\mathrm{BVT}\left(\mathrm{mgN} 100 \mathrm{~g}^{-1}\right)$} \\
\hline \multirow{3}{*}{ Ração } & Vivo & $14,40^{\mathrm{a}}$ & $13,23^{\mathrm{a}}$ & $13,75^{\mathrm{a}}$ & $12,96^{\mathrm{a}}$ & $13,76^{\mathrm{a}}$ \\
\hline & no gelo & $14,01^{\mathrm{a}}$ & $12,97^{\mathrm{a}}$ & $14,55^{\mathrm{a}}$ & $13,75^{\mathrm{a}}$ & $14,69^{\mathrm{a}}$ \\
\hline & DP & 1,63 & 0,58 & 1,53 & 1,06 & 1,38 \\
\hline \multirow{3}{*}{ Suínos } & Vivo & $13,09^{\mathrm{a}}$ & $13,30^{\mathrm{a}}$ & $12,50^{\mathrm{a}}$ & $13,88^{\mathrm{a}}$ & $14,10^{\mathrm{a}}$ \\
\hline & no gelo & $13,08^{\mathrm{a}}$ & $13,89^{\mathrm{a}}$ & $12,70^{\mathrm{a}}$ & $12,91^{\mathrm{a}}$ & $12,89^{\mathrm{a}}$ \\
\hline & DP & 2,19 & 1,78 & 1,20 & 1,17 & 2,35 \\
\hline \multirow{3}{*}{ Frangos } & Vivo & $11,67^{\mathrm{a}}$ & $13,70^{\mathrm{a}}$ & $13,29^{\mathrm{a}}$ & $12,49^{\mathrm{a}}$ & $12,90^{\mathrm{a}}$ \\
\hline & no gelo & $12,51^{\mathrm{b}}$ & $12,91^{\mathrm{a}}$ & $12,36^{\mathrm{a}}$ & $11,91^{\mathrm{a}}$ & $12,29^{\mathrm{a}}$ \\
\hline & DP & 0,72 & 1,59 & 1,48 & 1,45 & 1,07 \\
\hline Tratamento & Transporte & & & $\mathrm{pH}$ & & \\
\hline \multirow{3}{*}{ Ração } & Vivo & $6,4^{\mathrm{a}}$ & $6,5^{\mathrm{a}}$ & $6,4^{\mathrm{a}}$ & $6,4^{\mathrm{a}}$ & $6,1^{\mathrm{a}}$ \\
\hline & no gelo & $6,6^{\mathrm{a}}$ & $6,6^{\mathrm{a}}$ & $6,6^{\mathrm{b}}$ & $6,6^{\mathrm{b}}$ & $6,5^{\mathrm{b}}$ \\
\hline & DP & 0,19 & 0,20 & 0,16 & 0,14 & 0,32 \\
\hline \multirow{3}{*}{ Suínos } & Vivo & $6,7^{\mathrm{b}}$ & $6,7^{\mathrm{a}}$ & $6,6^{\mathrm{a}}$ & $6,6^{\mathrm{a}}$ & $6,4^{\mathrm{a}}$ \\
\hline & no gelo & $6,5^{\mathrm{a}}$ & $6,6^{\mathrm{a}}$ & $6,6^{\mathrm{a}}$ & $6,6^{\mathrm{a}}$ & $6,3^{\mathrm{a}}$ \\
\hline & DP & 0,14 & 0,12 & 0,13 & 0,09 & 0,17 \\
\hline \multirow{3}{*}{ Frangos } & Vivo & $6,8^{\mathrm{a}}$ & $6,8^{\mathrm{a}}$ & $6,8^{\mathrm{b}}$ & $6,8^{\mathrm{a}}$ & $6,3^{\mathrm{a}}$ \\
\hline & no gelo & $6,7^{\mathrm{a}}$ & $6,7^{\mathrm{a}}$ & $6,6^{\mathrm{a}}$ & $6,7^{\mathrm{a}}$ & $5,8^{\mathrm{a}}$ \\
\hline & DP & 0,11 & 0,10 & 0,12 & 0,11 & 0,48 \\
\hline Tratamento & Transporte & \multicolumn{5}{|c|}{ IP (mg peroxide $\mathrm{kg}^{-1}$ ) } \\
\hline \multirow{2}{*}{ Ração } & Vivo & $14,73^{\mathrm{a}}$ & $7,30^{\mathrm{a}}$ & $10,53^{a}$ & $13,51^{\mathrm{a}}$ & $10,01^{\mathrm{a}}$ \\
\hline & no gelo & $11,90^{\mathrm{a}}$ & $9,24^{\mathrm{a}}$ & $7,64^{\mathrm{a}}$ & $12,26^{\mathrm{a}}$ & $8,81^{\mathrm{a}}$ \\
\hline \multirow{4}{*}{ Suínos } & DP & 3,49 & 3,49 & 5,09 & 4,45 & 4,13 \\
\hline & vivo & $9,30^{\mathrm{a}}$ & $10,94^{\mathrm{a}}$ & $9,21^{\mathrm{a}}$ & $10,56^{\mathrm{a}}$ & $10,53^{\mathrm{a}}$ \\
\hline & no gelo & $11,08^{\mathrm{a}}$ & $9,07^{\mathrm{a}}$ & $8,81^{\mathrm{a}}$ & $11,68^{\mathrm{a}}$ & $11,08^{\mathrm{a}}$ \\
\hline & DP & 4,65 & 2,95 & 2,66 & 2,79 & 4,53 \\
\hline \multirow{3}{*}{ Frangos } & vivo & $8,87^{\mathrm{a}}$ & $7,20^{\mathrm{a}}$ & $10,28^{\mathrm{a}}$ & $4,88^{\mathrm{a}}$ & $8,23^{\mathrm{a}}$ \\
\hline & no gelo & $11,34^{\mathrm{a}}$ & $6,75^{\mathrm{a}}$ & $11,15^{\mathrm{a}}$ & $8,44^{\mathrm{b}}$ & $10,72^{\mathrm{a}}$ \\
\hline & DP & 3,79 & 2,93 & 3,44 & 3,21 & 3,81 \\
\hline Tratamento & Transporte & \multicolumn{5}{|c|}{ TBA (mg malonaldeído kg ${ }^{-1}$ ) } \\
\hline \multirow{3}{*}{ Ração } & vivo & $0,268^{\mathrm{a}}$ & $0,317^{\mathrm{a}}$ & $0,247^{\mathrm{a}}$ & $0,314^{\mathrm{a}}$ & $0,285^{\mathrm{a}}$ \\
\hline & no gelo & $0,201^{\mathrm{a}}$ & $0,406^{\mathrm{a}}$ & $0,382^{\mathrm{a}}$ & $0,272^{\mathrm{a}}$ & $0,289^{\mathrm{a}}$ \\
\hline & DP & 0,18 & 0,21 & 0,19 & 0,22 & 0,12 \\
\hline \multirow{2}{*}{ Suínos } & vivo & $0,165^{\mathrm{a}}$ & $0,190^{\mathrm{a}}$ & $0,241^{\mathrm{a}}$ & $0,289^{\mathrm{a}}$ & $0,216^{\mathrm{a}}$ \\
\hline & no gelo & $0,247^{\mathrm{a}}$ & $0,306^{\mathrm{a}}$ & $0,353^{\mathrm{a}}$ & $0,392^{\mathrm{a}}$ & $0,480^{\mathrm{b}}$ \\
\hline \multirow{4}{*}{ Frangos } & DP & 0,08 & 0,11 & 0,12 & 0,15 & 0,18 \\
\hline & vivo & $0,217^{\mathrm{a}}$ & $0,163^{\mathrm{a}}$ & $0,180^{\mathrm{a}}$ & $0,204^{\mathrm{a}}$ & $0,235^{\mathrm{a}}$ \\
\hline & no gelo & $0,066^{\mathrm{a}}$ & $0,111^{\mathrm{a}}$ & $0,127^{\mathrm{a}}$ & $0,203^{\mathrm{a}}$ & $0,224^{\mathrm{a}}$ \\
\hline & DP & 0,20 & 0,08 & 0,09 & 0,18 & 0,15 \\
\hline
\end{tabular}

Obs.: Médias seguidas de letras iguais na mesma coluna não apresentam diferença significativa $(\mathrm{P}>0,05)$. Quando houve diferença, foi aplicado o teste de Tukey com 95\% de confiança. DP = Desvio-padrão.

As variações na concentração de BVT em crómida verde Etroplus suratensis foram crescentes ao longo do período do experimento (LAKSHMANAN

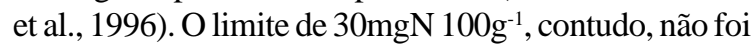
atingido mesmo após 20 dias armazenado em gelo. No presente trabalho, ao contrário, o BVT permaneceu praticamente constante até o $30^{\circ}$ dia. Os valores de BVT e pH no período das análises estiveram dentro dos estipulados pela legislação, 30mgN $100 \mathrm{~g}^{-1}$ de BVT e pH máximo de 6,8 (OETTERER, 2002; BONACINA, 2006).

Estudando o efeito do gelo clorado sobre parâmetros químicos e microbiológicos da carpa capim Ctenopharyngodon idella, SCHERER et al. (2004) encontraram valores baixos de BVT de músculo e pouca variação ao longo de 20 dias de armazenagem sob 
refrigeração $\left(3 \pm 1^{\circ} \mathrm{C}\right)$, com resultados inferiores aos encontrados no presente trabalho. $\mathrm{O} \mathrm{pH}$ do grupo tratado com a adição de cloro no gelo permaneceu com os valores abaixo do estipulado pela legislação brasileira: máximo de 6,8 (BRASIL, 2007a; BONACINA, 2006), enquanto o controle ultrapassou o limite no 5 o dia.

Avaliando as alterações bioquímicas postmortem de matrinxã Brycon cephalus procedente da piscicultura, mantido em gelo, BATISTA et al. (2004) obtiveram valores para $\mathrm{pH}$ entre 6,2 e 6,4, inferiores aos obtidos neste trabalho. Já os valores de BVT atingiram média de 33,3mgN $100 \mathrm{~g}^{-1}$ de músculo no 29ํ dia, acima do permitido pela legislação brasileira e superiores aos obtidos neste trabalho.

Não houve variação do IP nos tratamentos ração e dejetos de suínos. No tratamento dejetos de frangos, contudo, no 15을 dia o IP foi maior nas polpas dos peixes transportados vivos. Já o TBA não variou significativamente nos tratamentos ração e dejetos de frangos. No tratamento dejetos de suínos, no $30^{\circ}$ dia foi observado maior valor para a polpa das carpas transportadas no gelo. Durante o processamento para a obtenção do minced, as células se rompem e seu conteúdo em enzimas e ácidos nucléicos é exposto à oxidação, afetando a coloração, o sabor e a textura (OETTERER, 2002). A carne fica mais propensa à rancidez oxidativa e sujeita à menor aceitação pelo consumidor. No presente trabalho, os valores de IP e TBA foram baixos, possivelmente pela ausência de oxigênio, retardando a oxidação.

\section{CONCLUSÕES}

Os valores obtidos para BVT e pH estiveram sempre dentro dos valores estipulados pela legislação brasileira.

O processamento e os métodos de transporte de carpas vivas ou no gelo não afetaram a estabilidade lipídica da polpa de carpa húngara.

Os métodos de transporte (vivas ou no gelo) não afetaram a qualidade da polpa de carpa húngara Cyprinus carpio minimamente processada e embalada a vácuo.

\section{AGRADECIMENTOS}

Apoio financeiro do Conselho Nacional de Desenvolvimento Científico e Tecnológico (CNPq), Coordenação de Aperfeiçoamento de Pessoal de Nível Superior (CAPES) e UniSol - BANCO REAL. Agradecimento especial à EMATER, regional de Estrela, RS.

\section{REFERÊNCIAS}

A.O.A.C. Association of Official Analytical Chemist's Official Methods of Analysis. Washington, USA, 2000. 1018p. il.

BATISTA, G.M. et al. Alterações bioquímicas post-mortem de matrinxã Brycon cephalus (Günther, 1869) procedente da piscicultura, mantido em gelo. Ciência e Tecnologia de Alimentos, v.24, n.4, p.573-581, 2004.

BLIGH, E.G.; DYER, W.J. A rapid method of total lipid extraction and purification. Canadian Journal of Biochemistry and Physiology, v.37, n.8, p.911-917, 1959.

BONACINA, M.S. Desenvolvimento e caracterização de empanado a partir de corvina (Micropogonias furnieri). 2006. 115f. Dissertação (Mestrado em Engenharia e Ciência de Alimentos) - Fundação Universidade Federal do Rio Grande, Rio Grande, RS.

BONNELL, A.D. Quality assurance in seafood processing: a practical guide. New York: Chapman \& Hall, 1994. $641 p$.

BRASIL, Ministério da Agricultura. Regulamento da inspeção industrial e sanitária de produtos de origem animal, Brasília, DF, 2007a. Capturado em 08 ago. 2007. On line. Disponível em: http://www.fabricadoagricultor. pr.gov.br/arquivos/File/RISPOA.pdf. 154p.

BRASIL. Métodos Analíticos Oficiais para Controle de Produtos de Origem Animal e seus Ingredientes. Métodos Físico-químicos. Brasília, 2007b. Capturado em 08 ago. 2007. On line. Disponível em: http://extranet.agricultura. gov.br/sislegis-consulta/servlet/VisualizarAnexo?id=2321. $115 p$.

BRASIL. Agência Nacional de Vigilância Sanitária (ANVISA). Resolução RDC n. 360, de 26 dez, 2003. 8p. Capturado em 08 ago. 2007. On line. Disponível em: http://e-legis.bvs.br/ leisref/public/showAct.php?id=9059\#'

BRESSAN, M.C. Tecnologia de pós-colheita em peixes. 2001. 106f. Monografia (Especialização em Piscicultura) Curso de pós-graduação "lato sensu” à distância, Universidade de Lavras, Lavras, MG.

FRANCO, G. Tabela de composição química dos alimentos. 9.ed. São Paulo: Atheneu, 1992. 307p.

FRAZIER, W.C.; WESTHOFF, D.C. Food microbiology. 4.ed. New York: Mc Graw-Hill, 1998. 681p. il.

HUSS, H.H. El pescado fresco: su calidad y cambios de calidad. Manual de capacitación preparado por el programa de capacitación FAO/DANIDA em tecnología pesquera y control de calidad. Roma: FAO, 1988. 132p. (Colección FAO: Pesca, n. 29).

LANIER, T.C.; LEE, C.M. Surimi technology. New York, USA: Marcel Dekker, 1992. 528p.

LAKSHMANAN, P.T. et al. Nucleotide degradation and quality changes in mullet (Liza corsula) and pearlspot (Etroplus 
suratensis) in ice and at ambient temperatures. Food Control, v.7, n.6, p.277-283, 1996.

LEISTNER, L.; RODEL, W. The stability of intermediate moisture foods with respect to microorganisms. In: DAVIES, R. et al. Intermediate moisture foods. Pergamon, USA: Elsevier, 1976. p.120-130.

MAIA, E.L. Composição, conservação e utilização do curimbatá Prochilodus scrofa Steindachner. 1980. $129 f$. Dissertação (Mestrado em Tec. de Alimentos) - FEAUNICAMP.

NEIVA, C.D.P. Valor agregado $\mathbf{x}$ qualidade do pescado. Capturado em 15 out. 2004. On line. Disponível na internet: www.pescabrasil.com.br.

OETTERER, M. Industrialização do pescado cultivado. Guaíba: Agropecuária, 2002. 200p.

RIBEIRO, A.R. et al. Manejo pré-abate e bioquímica da carne de pescado. Revista Aqüicultura \& Pesca, Ano I, n.9, p.2433, 2005.

SÁ, E. Conservação do pescado. Revista Aqüicultura \& Pesca, Ano I, n.1, p.20-26, 2004.

SAINZ, R. L. Estudo tecnológico para o desenvolvimento de um produto minimamente processado à base de carpa- capim (Ctenopharyngodon idella). 2001. 97f. Dissertação (Mestrado em Ciência e Tecnologia de Alimentos) - FURG, Rio Grande, RS.

SAKER-SAMPAIO; VIEIRA, R.H.S.F. Manuseio do pescado a bordo. In: VIEIRA, R.H.S.F. Microbiologia, higiene e qualidade do pescado. São Paulo, SP: Varela, 2003. p.2536.

SCHERER, R. et al. Efeito do gelo clorado sobre parâmetros químicos e microbiológicos da carne de carpa capim Ctenopharyngodon idella. Ciência e Tecnologia de Alimentos, v.24, n.4, p.680-684, 2004.

SEAFOOD. Vacuum and atmosphere packaged fish and fishery. Capturado em 20 maio 2006. Online. Disponível em http://seafood.ucdavis.edu/haccp/compendium/hapt08.htm.

SOUZA, M.L.R. Industrialização, comercialização e perspectivas. In: MOREIRA, H.L.M. et al. Fundamentos da moderna aqüicultura. Canoas: Ulbra, 2001. p.149-189.

STANSBY, M.E. Industrial fishery technology. London: AVI, 1968. 393p.

VIEGAS, E.M.M. Rigor mortis em peixes. In: AQUACIÊNCIA 2004, Vitória, ES. Anais... Vitória, ES: Aquabio, 2004. V.1, p.23. 